\title{
Strengths, weaknesses, opportunities and threats (SWOT) analysis of Environmental NGOs working in Punjab, Pakistan
}

\author{
Lina Maqbool, Nauman Ahmed, Muhammad Umar Hayyat ${ }^{\star}$, Rashid Mahmood, Zawar Haider \\ and Rab Nawaz
}

Sustainable Development Study Centre, GC University Lahore, Pakistan.

Accepted 02 January, 2014

\begin{abstract}
The objective of this study is to analyze the working potential of Environmental Non-Governmental Organizations (ENGOs) in Punjab, Pakistan. Semi-structured questionnaire was designed to fulfill the rationale of the study. The potential of working of ENGO is based on the various factors such as financial support, acceptability by the local community, qualification of the staff and social threats while working. Descriptive analysis and Pearson Chi-Square were applied on the collected data to find out the percentage and association. The results showed that operative structure of $65.4 \%$ of the ENGOs is volunteer based. Only $\mathbf{4 2 . 3 \%}$ of ENGOs are working on the environmental issues while, others have mixed working scope and vision. There is a lack of auditing system to check the efficient utilization of the resources. A mechanism of self-reporting has been developed by the ENGOs to report to their donors. There is a strong relationship between the number of the staff, age and the strength of the ENGO. It was also found that ENGOs working in Punjab, Pakistan are not being effected by the political parties and having minor social threats. The analysis also showed that the working ENGOs lack the funding which immobilizes them to work efficiently. Many ENGOs have stopped working but their names are still present in the list of the registered ENGOs. There is vital need to update list of ENGOs by concerned departments and to properly mechanize the system of monitoring and auditing.
\end{abstract}

Key words: Operative structure, scope, social threats, political interference, technical expertise.

\section{INTRODUCTION}

Non-Governmental Organizations (NGOs) are playing an important role in strengthening the base of civil society. The more mature the civil society is the more working NGOs they have (Mostashari, 2005). The failure in governmental responsibilities due to a large number of reasons causes a shift in the behavior of the international donors from public to private sector as a preferable channel for aid, funding and support in the political or economic perspectives (Charlton, 1995; Vakil, 1997). NGOs dealing with environmental issues are known as ENGOs (Environmental Non-Governmental Organization).
Earth Summit in 1992 took place in Rio De Janeiro which laid the base of ENGO on the International Scale (Smith, 1995). ENGOs work on the international scale to make communication stronger. The number of NGOs since the start of twenty-first century is increasing. Their growth is faster than the governmental organizations. Working of NGOs becomes efficient by studying target groups, contributed factors, assessment activities, output and the study of the short-term effects on the community (Racine et al., 2013). The spectrum of the ENGOs is broad and varies among the different parts of the world. 
Table 1. Operative structure of the ENGOs in Punjab, Pakistan.

\begin{tabular}{lcc}
\hline No.Structure of working ENGO & Frequency & Percent \\
\hline 1. Paid & 6 & 23.1 \\
2. Volunteers & 17 & 65.4 \\
3. Any other & 2 & 7.7 \\
4. All & 1 & 3.8 \\
Total & 26 & 100.0 \\
\hline
\end{tabular}

The balanced growth of ENGOs has made policy makers, activists, and analysts more conscious (Smith, 1995). This leads some observers to claim that ENGOs are in the midst of a quiet revolution (Edwards and Hulme, 1996). Despite the increase in their budget, scale and range, ENGOs are not well documented and analyzed (Bebbington, 2004). In most countries no one monitors their activities. The few works that focus on the field operations of ENGOs seldom consider more than one organization (Bebbington, 2004). Evaluation checks the effectiveness of the working NGOs. This approach is known as Evaluability assessments (EAs) (Tucker, 2005). A systemic approach is used to describe the credibility and viability of NGOs programs (Smith, 2010). For this purpose questionnaire based studies are carried out in most parts of the world. This helps in studying the problems more closely (O'Dwyer and Unerman, 2008). Pakistan faces various environmental issues such as solid waste management, deforestation, lack of renewable energy sources (Bhutto et al., 2011), unhygienic conditions (Klinkenberg et al., 2004), radon and pesticides pollution (Faheem and Matiullah, 2008), lack of access to safe drinking water, improper sewerage systems, noise pollution (Azizullah et al., 2011), air pollution, groundwater contamination, surface water contamination (Tariq et al., 2004) and melting of glaciers because of the climate change. The State seems to fail to address these issues. ENGOs are working on these issues with the help of the international donors and government organizations (Bhutto et al., 2011). According to our information any study has not been done in our country to assess the working potential of the ENGOs. Keeping in view this shortcoming, the present was designed. This study can be helpful in understanding the problems associated with the ENGOs working in Punjab, Pakistan. Major objectives of the present study were to analyze the working potential, achievements and actively working ENGOs working in Punjab, Pakistan.

\section{MATERIALS AND METHODS}

The sample selection procedure was used for analysis. For the purpose of the study questionnaire based study was conducted in the Punjab Province of Pakistan. The questionnaire was then analyzed by using the tool of the Statistical Package for Social Sciences (SPSS).
The followings are the Acts which are followed for ENGO Registration in Punjab, Pakistan:

1. Voluntary Social Welfare Agencies by Ordinance of 1961(

Registration and control)

2. Societies Registration Act of 1860

3. Trust Act of 1882

4. Charitable Endowment Act, 1890

5. Cooperative Societies Act, 1925

6. Companies Act, 1984

From the following departments the list of registered ENGOs was collected:

1. Security and Exchange Commission of Pakistan (SECP), Lahore

2. Social Welfare Department (SWD), Lahore

3. District Office (DO), Environment District Govt., Lahore

4, Industrial Unit (Ponch House)

5. Environmental Protection Department (EPD), Lahore

6. International Union for the Conservation of Nature (IUCN), Islamabad

\section{RESULTS}

In Lahore, there are 6 ENGOs working according to the Voluntary Social Welfare Act and 86 ENGOs had been registered according to the Society Act. There were total 66 ENGOs which were registered according to the Voluntary Social Welfare Act in Punjab other than Lahore. Out of these 66 in Punjab only 46 were working. There were total 158 ENGOs in all over the Punjab.

\section{Operative structure and scope}

Surveyed based result showed that $65.4 \%$ of surveyed ENGOs have voluntary based operative structure, $23.1 \%$ of ENGOs have paid voluntary operative structure $7.7 \%$ of the ENGOs have operating structure; only $3.8 \%$ of the ENGOs have the operating structure that is based on all the 3 categories (Table 1). During the process of registration ENGOs, it is compulsory to state their scope of working; only $42.3 \%$ of the NGOs have stated their vision as environment; whereas, ENGOs that are working on the environmental issues in their areas did not state their vision as the environment. These ENGOs primarily stated their vision as Prevention (7.7\%), Health (7.7\%), Conservation (7.7\%), Education (3.8), Women Empowerment $(3.8 \%)$ and others (3.8\%). Only $23.1 \%$ of the registered NGOs have the scope of working based on all categories (Table 2).

\section{Association of age and number of workers and strength of working}

Results displayed that age of the ENGO has a positive relationship with strength. More than 10 years category showed $30.77 \%$ strength in working. While lower age category of $1-5$ years has very less strength of $3.85 \%$ 
Table 2. ENGOs scope of working in Punjab, Pakistan.

\begin{tabular}{lcccc}
\hline No.Scope of Organization Frequency & Percent & Valid Percent & Cumulative Percent \\
\hline 1. Environment & 11 & 42.3 & 42.3 & 42.3 \\
2. Prevention & 2 & 7.7 & 7.7 & 76.9 \\
3. Education & 1 & 3.8 & 3.8 & 50.0 \\
4. Health & 2 & 7.7 & 7.7 & 57.7 \\
5. Conservation & 2 & 7.7 & 7.7 & 65.4 \\
6. Women Empowerment & 1 & 3.8 & 3.8 & 69.2 \\
7. Others & 1 & 3.8 & 3.8 & 46.2 \\
8. All & 6 & 23.1 & 23.1 & 100.0 \\
Total & 26 & 100.0 & 100.0 & \\
\hline
\end{tabular}

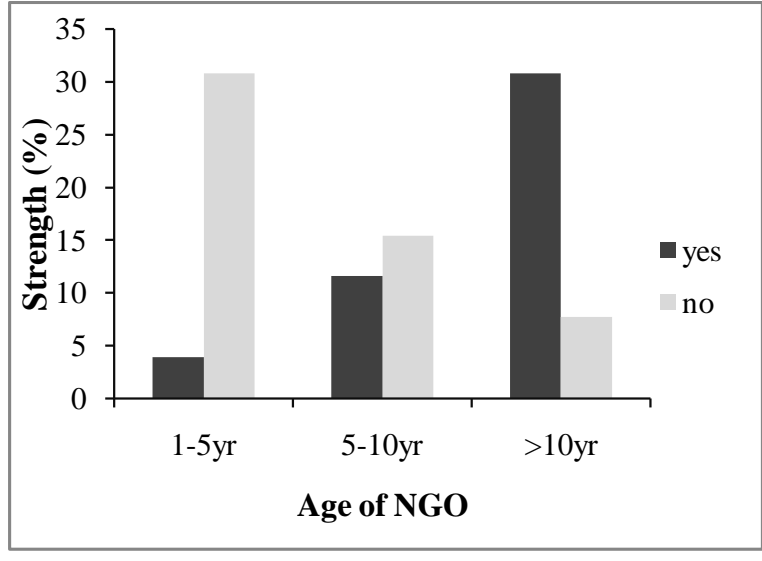

a

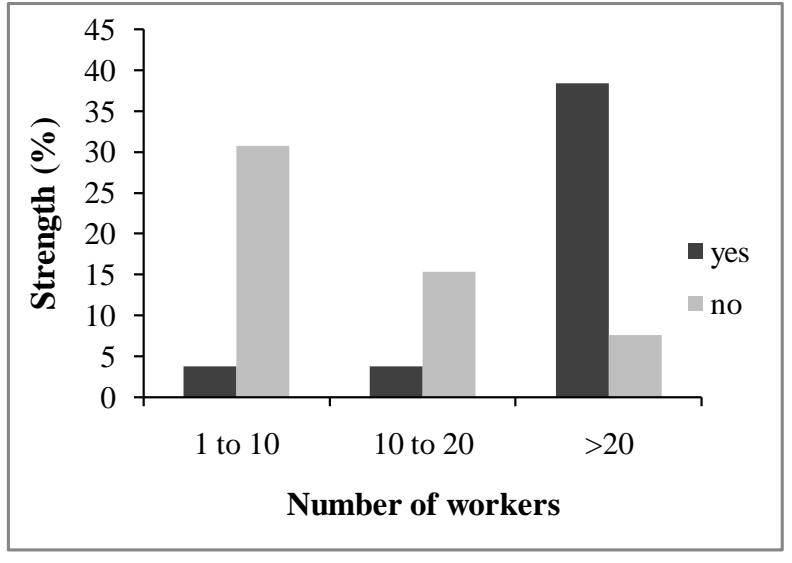

b

Figure 1. Association between age and strength of working (a), number of workers and strength of working (b) in ENGO.

and $5-10$ years group showed $11.54 \%$ strength in working. By applying Pearson chi-square test of association, significant results ( $p$-value 0.011 ) showed association between age of ENGO and its strength of working. Survey based analysis showed that strength of the ENGO has a positive relationship with the numbers of the workers. The organization has the more strenght if the numbers of the workers associated with them increase. According to our defined categories more than 20 workers hosted category has showen more strength $(38.46 \%)$ in working as compared to $1-10$ workers (3.85\%). Pearson chi-square was applied and result gave the significant $p$-value of 0.002 . It means that there is assocaition between number of workers and strength of ENGO (Figure 1a and 1b).

\section{Association between availability of technical expertise and accountability and strength of working}

Analysis based on our survey presented that strength of the ENGO increases as the number of working technical expertises increases. Government provides techanical help to the $53.85 \%$ of the ENGOs, whereas $46.15 \%$ of the ENGOs do not get an aid from the government. Pearson Chi Square result showed the significance and positive relationship between the two varaibles (Figure 2a). Results displayed that accountability of the ENGO is responsible for developing positive relationship with the strength of working ENGO. Survey presented that $46.15 \%$ and $19.23 \%$ of the ENGOs are accountable but they do not have the proper working mechanism. Only $34.62 \%$ of the ENGOs have no accountability mechanism. Fisher's exact test is applied due to expected count less than 5; result was significant (P-value 0.001), which means that there is also association between accountability in ENGO and strength in working (Figure 2b).

\section{Associations between social threat and age of working}

The study revealed that there is no association between age of working ENGO and associated social threat. 


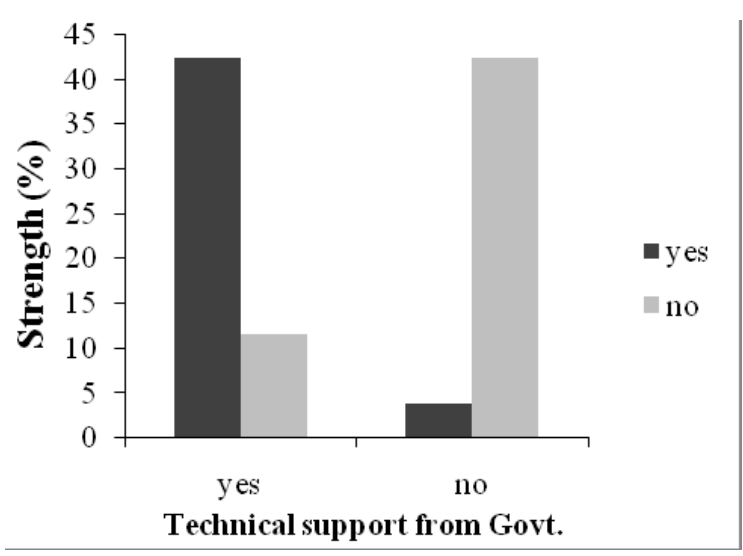

a

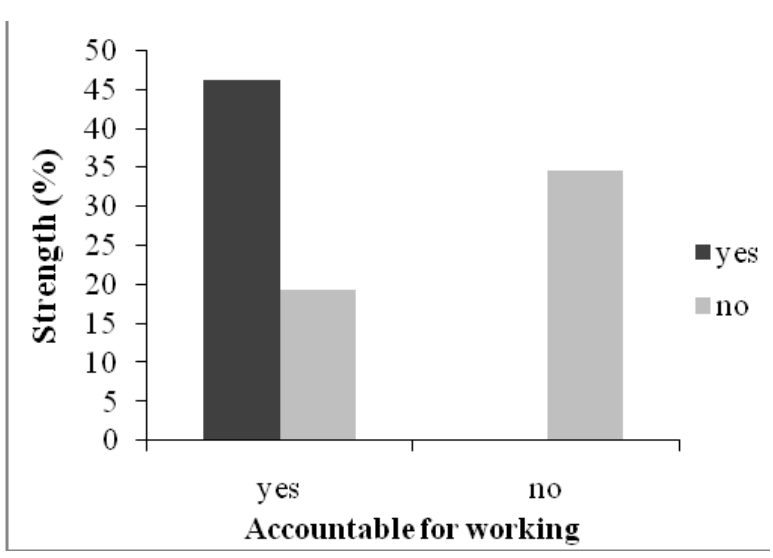

b

Figure 2. Association between availability of technical expertise and strength of working (a), association between accountability and strength of working (b) in ENGO.

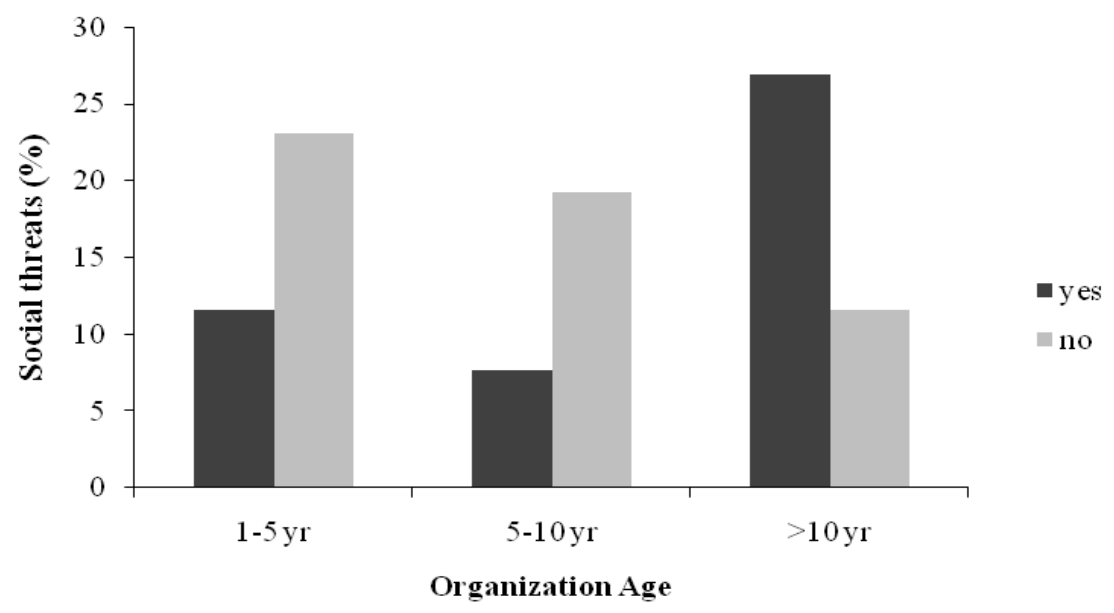

Figure 3. Associations between social threat and age of working ENGO.

Pearson Chi-Square was applied to find the association between the various variables; the results gave an insignificant value ( $p$-value, 0.153 ), which means that there is no association between age of working and social threat. A clustered bar diagram showed that there is more threat $(26.92 \%)$ in more than 10 years but there is no significant difference in others groups as well (Figure 3).

\section{Association between social threat and political interference}

Political interference showed no association between social threats of ENGO. Fisher's exact result was insignificant ( $p$-value 0.117 ), which means that there is no association between social threat and political interference. While working $19.23 \%$ of the ENGOs face political threats, whereas $80.77 \%$ of the ENGOs do not face social threats and political interference while working (Figure 4).

\section{Association between sufficient budget and sustainable working}

Budget is required for sustaining the working of the organization. Statistical analysis is applied which shows that there is the positive relation between the amount of the budget and sustainability of the working. Fisher's exact result significantly ( $p$-value 0.028 ) showed association between both of them. ENGOs working are sustainable and they have sufficient amount of the budget, that is, $76 \%$ whereas $24 \%$ of the ENGOs do not have the sufficient amount of the budget for their working 


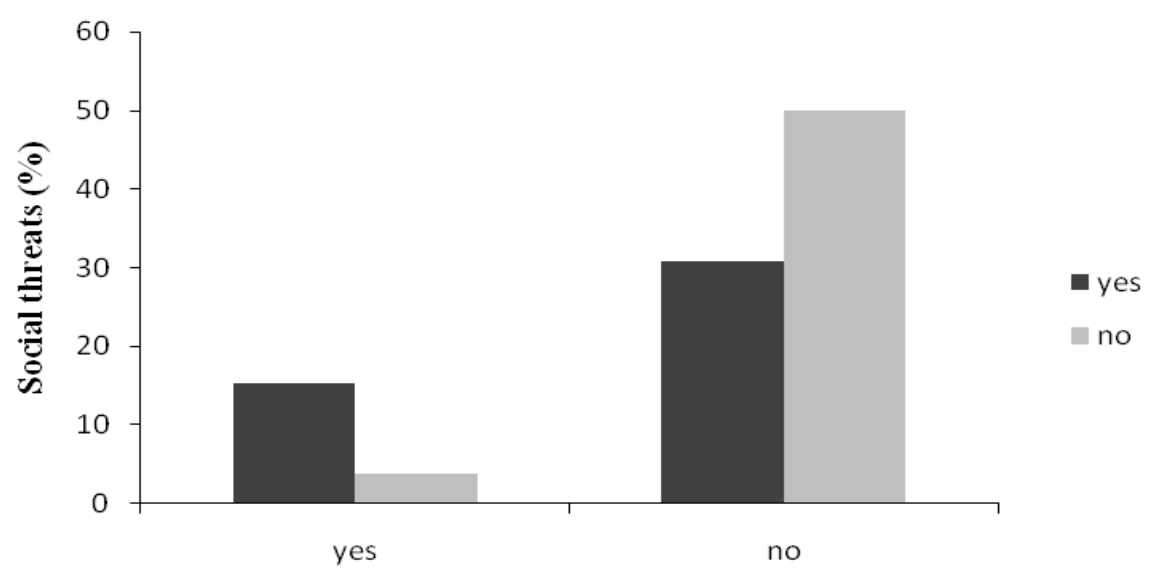

Social threats faced

Figure 4. Association between social threat and political interference.

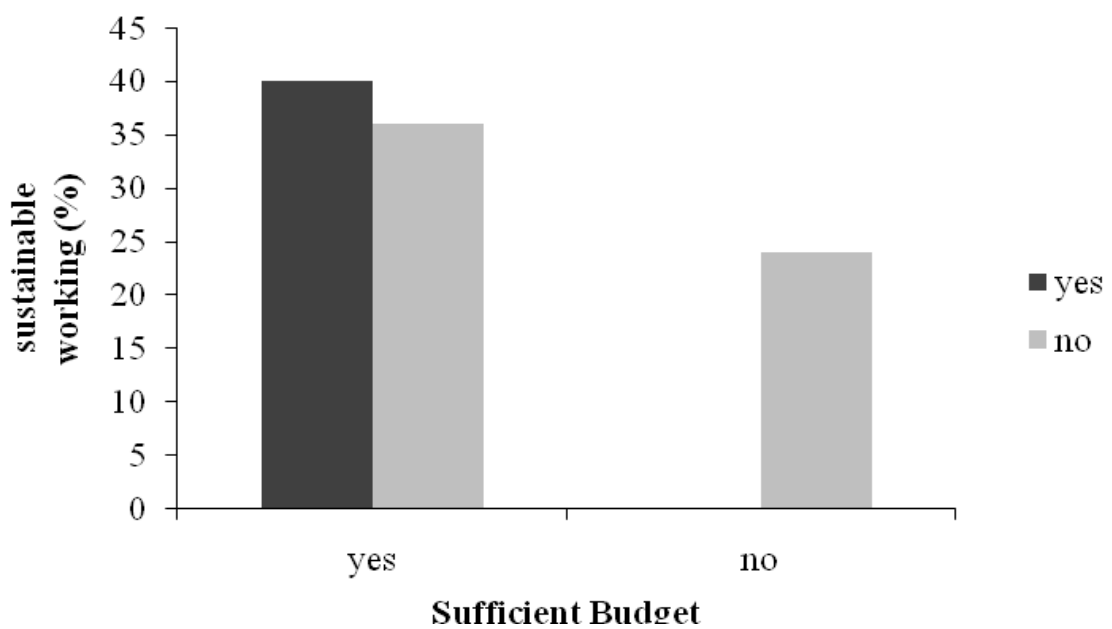

Figure 5. Association between sufficient budget and sustainable work.

(Figure 5).

\section{DISCUSSION}

The role of the ENGOs is substantial in the improvement of environment. ENGOs are playing their central role in the developed world where people are concerned about their environmental problems but in the developing countries ENGOs are still in the state crisis because of the lack of the funding. ENGOs play an intermediary role in linking the government, public and the private sector (Moon and Park, 2004). The emphasis of the study is to find out the working potential of the ENGOs working on the grass-root level. The results of analysis showed that there is a strong association between the number of workers and their technical expertise with the strength of the organization. The effects of social threats and political intrusion on the working of grass-root level ENGOs are also studied. The scope and the vision of the ENGOs are important to clarify their area of working. ENGOs that are working on the environmental issues in Punjab are not solely based on the environment objective rather they have mixed objectives based on the varying issues. Over the last five years the funding of the $69.23 \%$ of the ENGOs has increased. ENGOs attract diversified portfolio of grants or contracts at national and international scale. The funding and strength of the working ENGOs have a positive relationship (Meyer, 1995). Local and international community demands the less expenditure on the management and administration staff as compared to the expenditures of cost of running the project for the community (Gugerty, 2009). ENGOs are known to be more cost effective in providing the basic social services to the poor but lack the proper auditing system, which is the main cause of the hindrance (Ebrahim 2003). 
The main cause of crisis of the ENGOs is the lack of accountability and transparency assurance mechanism in the system of working which causes damage to the creditability of the ENGOs.

Findings of this study argument the study conducted by Brass (2012) which stated that political pressure does not appear to influence ENGOs working in Kenya. In some areas, the social norms are appropriate to accept and apply on the larger scale to continue the proper working of the ENGO (Bloodgood and Tremblay-Boire, 2011). Driessen (2004) conducted the SWOT analysis and come with the same results. Hence, the more experience an ENGO has the more efficiently it will work. If an ENGO has the budget to run a project then it will be working for the betterment of the community. Sustainability in the sense of running the project is running a project for longer period of time and benefiting maximum people; whereas, the less the political influence the more the chance of the efficient working. Study also conducted by the Lehman (2007) showed that proper accountability mechanism is really important for the proper working of the ENGO and to enhance its efficiency or validity. According to the study most of the ENGOs claim a proper mechanism of the accountability. Instead of keeping the accounts and reporting it to the donors, it was indeed a difficult task to provide information. It is quite evident from the study that ENGOs need proper infra-structure, staff, technical and financial aid from the government. Hence, most of the ENGOs are working at the local level and being funded by the local people. Most of the registered ENGOs are dead or inactive now because of lack of resources.

\section{Conclusion}

There is a strong significant relationship between the number of the years since the ENGO is working and its strength. In Punjab, Pakistan ENGOs are not being affected by the political parties and having less social threats. For the accountability of the ENGOs, no proper mechanism exists. For updating information and issues, ENGOs have no proper mechanism. It is recommended that list of ENGOs should be updated regularly, inactive orga-nizations should be removed from list and accountability mechanism must be devised.

\section{ACKNOWLEDGEMENTS}

The authors appreciatively acknowledged the Sustainable Development Study Centre, Government College University Lahore for providing support to carry out this study and Social Welfare Department (SWD) Lahore, Security and Exchange Commission of Pakistan (SECP) and other departments for providing data.

\section{REFERENCES}

Azizullah A, Khattak MNK, Richter P, Häder DP (2011). Water Pollution in Pakistan and its Impact on Public Health-a Review. Environ. Int. 37(2):479-497.

Bebbington A (2004). NGOs and Uneven Development: Geographies of Development Intervention. Prog. Hum. Geog. 28(6):725-745.

Bhutto AW, Bazmi AA, Zahedi G (2011). Greener Energy: Issues and Challenges for Pakistan-Biomass energy prospective. Renew. Sust. Energ. Rev. 15(6):3207-3219.

Bloodgood EA, Tremblay-Boire J (2011). International NGOs and National Regualtion in an Age of Terrorism. Voluntas 22:142-173.

Brass JN (2012). Why Do NGOs Go Where They Go? Evidence from Kenya. World Dev. 40(2):387-401.

Charlton R (1995). NGOs, Politics, Projects and Probity: a Policy Implementation Perspective. Third World Q. 16(2):237-256.

Driessen M (2004). Strength Weakness Analyses on the ILO as a Model for NGO Participation. Ebrahim A (2003). Accountability in practice: Mechanisms for NGOs. World Dev. 31(5):813-829.

Edwards M, Hulme D (1996). Too Close for Comfort? The Impact of Official Aid on Nongovernmental Organizations. World Dev. 24(6):961-973.

Faheem M, Matiullah X (2008). Indoor Radon Concentration Levels in Several Districts of the Punjab Province-Pakistan. Radiat. Meas. 43:380-384.

Gugerty MK (2008). The Efectiveness of NGO Self-regulation: Theory and Evidence from Africa. Public Adm. Dev. 28:105-118.

Klinkenberg $E$, Konradsen F, Herrel N, Mukhtar M, Hoek W, Amerasinghe FP (2004). Malaria Vectors in the Changing Environment of the Southern Punjab, Pakistan. Tran. R. Soc. Trop. Med. Hyg. 98 (7):442-449.

Lehman G (2007). The Accountability of NGO in Civil Society and its Public Spheres. Crit. Pers. Account. 18:645-669.

Meyer CA (1995). Opportunism and NGOs: Entrepreneurship and Green North-souths Transfers. World Dev. 23(8):1277-1289.

Moon KH, Park DK (2004). The Role and Activities of NGOs in Reforestation in the Northeast Asian region. Forest Ecol. Manag. 201:75-81.

Mostashari A (2005). An Introduction to Non-governmental Organizations (NGO) Management. Iranian Studies Group at MIT.

O'Dwyer B, Unerman J (2008). The Paradox of Greater NGO Accountability: A Case Study Of Amnesty Ireland. Account. Org. Soc. 33:801-824.

Racine LD, Dagenais C, Ridde V (2013). An Evaluability assessment of a West Africa Based Non-Governmental Organization's (NGO) Progressive Evaluation Strategy. Eval. Program Plann. 36:71-79.

Smith BH (1995). The Road from Rio: Sustainable Development and the Nongovernmental Movement in the Third World. Voluntas: Int. J. Volunt. Nonprof. Org. 6:101-106.

Smith MF (2010). Evaluability Assessment. In S. Mathison (Ed.), Int. J. Hum. Ecol. 11(1):65-74.

Tariq MI, Afzal S, Hussain I (2004). Pesticides in Shallow Groundwater of Bahawalnagar, Muzafargarh, DG Khan and Rajan Pur districts of Punjab, Pakistan. Environ. Int. 30(4):471-479.

Tucker JG (2005). Feasibility. In: Mathison S (Ed.), Encyclopedia of Evaluation. Thouasnd Oaks, CA: Sage.

Vakil AC (1997). Confronting the Classification Problem: Toward a Taxonomy of NGOs. World Dev. 25(12):2057-2070. 